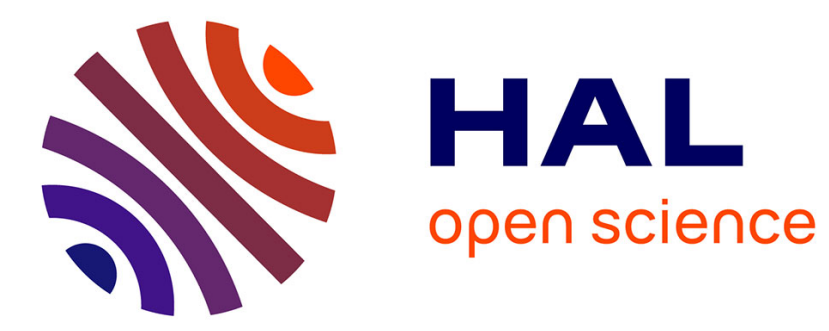

\title{
SCANNING AUGER MICROANALYSIS AT HIGH ENERGY PROBES
}

\author{
M. Tholomier, P Morin, E. Vicario, N. Mubanga
}

\section{To cite this version:}

M. Tholomier, P Morin, E. Vicario, N. Mubanga. SCANNING AUGER MICROANALYSIS AT

HIGH ENERGY PROBES. Journal de Physique Colloques, 1984, 45 (C2), pp.C2-309-C2-312. 10.1051/jphyscol:1984269 . jpa-00223983

\section{HAL Id: jpa-00223983 https://hal.science/jpa-00223983}

Submitted on 1 Jan 1984

HAL is a multi-disciplinary open access archive for the deposit and dissemination of scientific research documents, whether they are published or not. The documents may come from teaching and research institutions in France or abroad, or from public or private research centers.
L'archive ouverte pluridisciplinaire HAL, est destinée au dépôt et à la diffusion de documents scientifiques de niveau recherche, publiés ou non, émanant des établissements d'enseignement et de recherche français ou étrangers, des laboratoires publics ou privés. 


\title{
SCANNING AUGER MICROANALYSIS AT HIGH ENERGY PROBES
}

\author{
M. Tholomier, P. Morin, E. Vicario and N. Mubanga \\ Université Claude Bernard, Lyon I, Département de Physique des Matériaux, \\ 43 Boulevard du 11 Novembre 1918, 69622 Vilieurbanne Cedex, France
}

\begin{abstract}
Résumé - Des expériences de microanalyse Auger sur des îlots d'argent de dimensions de l'ordre de $50 \mathrm{~nm}$ - $200 \mathrm{~nm}$ sont décrites. Le rapport de Ia hauteur du pic Auger sur le fond continu ainsi que la résolution spatiale sont interprétés à l'aide des électrons rétrodiffusés.

Abstract - MicroAuger analysis on silver islands with $50 \mathrm{~nm}$ to $200 \mathrm{~nm}$ size, are described. Auger peak height to background ratio and spatial resolution are interpreted by means of backscattered electrons.
\end{abstract}

\section{I - Introduction}

The last decade has witnessed a phenomenal growth of interest in Auger electron spectroscopy (AES). Today, it is probably the most widely used of all surface analytical techniques. This development has became possible with the advances in vacuum technology which permit to maintain an uncontamined surface and the progress in electronic detection of a spectrum (1). Improvements were achieved by the introduction of high brightness guns based upon $\mathrm{LaB}_{6}$ thermoionic or the $W$ field emission cathodes. Different electron sources have been compared and the limitation of spatial resolution by backscattered electrons effects have begun to be investigated (2). The field emission gun (FEG) has emerged as having very considerable advantages for all studies requiring a resolution better than $100 \mathrm{~nm}$.

Many surface processes, such as nucleation or crystals growth are extremely inhomogeneous and complicated. So there is an intense interest, not only to improve the spatial resolution of surfaces techniques, but also to dispose of ultra-high vacuum specimen and/or analysis chambers containing several facilities to characterize a sample : possibility of transmission electron microscopy observations, high reflection energy electron diffraction (RHEED), low energy electron diffraction (LEED) ....

In this paper, we present and analyse some microAuger analysis results, in the $50 \mathrm{~nm}$ - $350 \mathrm{~nm}$ range, carried out on silver clusters deposited on a silicon substrate. The $\mathrm{N}(\mathrm{E})$ distributions in the energy range $5-60 \mathrm{keV}$ around the $356 \mathrm{eV}$ silver $M_{4}$ VV and $351 \mathrm{eV}$ silver $M_{5}$ VV Auger peaks have been recorded and the Auger peak height/background ratio has been deduced. Change of this ratio as a function of energy has been studied. Interpretation of these variations is made using backscattered electrons distribution. Detection ability of 50 nm size silver clusters at $50 \mathrm{keV}$ primary energy has been shown and this one remains better than $200 \mathrm{~nm}$ at $20 \mathrm{keV}$ and lower energies.

\section{II - The instrument}

The experiments described were performed on HB 50 scanning electron microscope (3) (4), with an ultra high vacuum (UHV) specimen chamber, manufactured by V.G. Microscope Ltd. In routine conditions, the analysis chamber pressure and the specimen chamber pressure are nomally $130 \mathrm{nPa}$ and $650 \mathrm{nPa}$ respectively. After overnight baking at $473 \mathrm{~K}$ and outgassing of all filaments and sources, the analysis chamber pressure and the specimen chamber pressure reach $13 \mathrm{nPa}$ and $65 \mathrm{nPa}$. These pressures are adequate for many Auger electrons spectroscopy studies without appreciable contamination problems. 
The microscope uses a field electron emitting gun with a [310] tungsten tip. The gun is a two element electrostatic type with continuous operation from 2.5 up to $60 \mathrm{keV}$. A scintillator and a photomultiplier assembly are utilised for standard SEM imaging. For this mode, the spatial resolution is better than $10 \mathrm{~nm}$ at energies higher than $50 \mathrm{keV}$. At $50 \mathrm{keV}$, the sample current detected is $3 \cdot \mathrm{x} 10^{-9} \mathrm{~A}$ with a $500 \mu \mathrm{m}$ objective aperture for an emission current of $2 \times 10^{-5} \mathrm{~A}$. At primary energy lower than $7.5 \mathrm{keV}$, the spatial resolution remains better than $35 \mathrm{~nm}$. The ratio of the sample current with an $500 \mu \mathrm{m}$ objective aperture and without aperture is about $20-25$ and is almost constant on the whole energy range.

The Auger electron detection system is made of concentric hemispherical analyser fitted with a retarding grid and an Einzel input lens. The analyser can be operatedin two modes : the constant analyser energy (CAE) and the constant retarding ratio (CRR) (5). In CAE mode, the hemispheres are operated at constant pas energy $\mathrm{E}_{\mathrm{p}}$. The retarding field on the input lens is varied in order to sweep through ${ }_{a} \mathrm{p}$ spectrum. This mode gives a constant bandwidth $\Delta E$ which is useful for a faithful reproduction of $\mathrm{N}(E)$ spectra and eliminates the artifacts resulting from peak shape changes. In CRR mode, the input grid is operated at constant retard ratio and the analyser pass energy is swept to record a spectrum. This mode has constant resolving power $E_{p} / \Delta E$ and is useful to obtain larger Auger signals at higher energies or to reduce the background influence at low energies. The constant retard ratio $C R R$ is defined by $C R R \simeq(E / E)$, with $E$ kinetic energy of sample emitted Auger electrons. The choosen ratio $p_{S}$ usually $e_{1}$ or possibly 2 . In normal runs, higher values of CRR are not much used because the total collection efficiency, including instrumental geometrical collection efficiency, and energy collection efficiency, is too low (about $10^{-3}$ ) and doesn't permit to obtain adequate Auger peaks heights. Auger line broadening introduced by the analyser can be determined using formula derived by Kuyatt and Simpson (6). So for the mode CRR $=1$, the two $M_{4}$ VV silver peaks can't be correctly separated $(\Delta E \simeq 7 \mathrm{eV})$. Auger spectra were obtained in the $N(E)$ mode either by a standard lock-in technique with beam blanking or by pulse counting technique.

\section{III- Results and discussion}

To study the ability of SEM to microAuger analysis, we examined a sample composed of silver clusters evaporated with a rare gas atmosphere (helium $-1.3 \times 10^{4} \mathrm{~Pa}$ ) on a silicon substrate in a separate vacuum system.

Auger analysis were made using the $M_{4}$ VV silver Auger transition. A first spectra was recorded after a preliminary etching ( 2 minutes) by argon ion bombardment $[E=4 \mathrm{keV}, I=20 \mu \mathrm{A}]$ to decontaminate the superficial layers of the sample. After repetitive scans no significant changes in Auger peak height and background were seen indicating negligible electron beam induced effects. The ratio of Auger peak height to background has been plotted as a function of energy in Figure 1 assuming the background proportional to the intensity of the primary beam. The observations were made on a cluster of about $300 \mathrm{~nm}$ size in CRR $=1$.

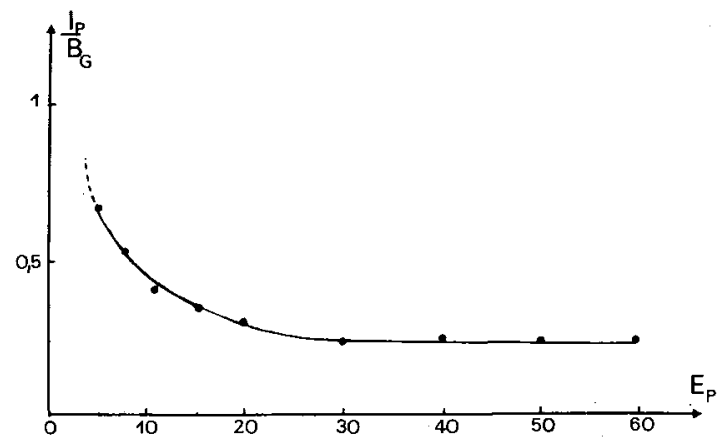

Fig. 1 - The Auger peak height to background ratio plotted against the primary energies : $351 \mathrm{eV}$ silver peak, mode $\mathrm{N}(\mathrm{E}), \mathrm{CRR}=1$, current : $1 \mathrm{nA}$, sweep : $0.4 \mathrm{~V} / \mathrm{s}$, time constant : $\tau=3 \mathrm{~s}$. 
The graph of figure 1 indicates a high increase of the ratio Auger peak height to background at energies lower than $20 \mathrm{keV}$ and small changes of this ratio at higher energies. According to Shimizu's calculations (7), for MVV ( 350 eV) silver transitions, the contributions of backscattered electrons and of primary electrons to the intensity of Auger electron peak are approximately equal for an primary energy of $15 \mathrm{keV}$. At lower energies, the contribution of backscattered electrons is nearly constant whereas the contribution of primary electrons is strongly increased. For high excitation energies, Auger peak intensity decreases owing to the reduction of the cross-section for ionization of inner shells. Bethe or Gryzinski formulae (8) indicate that for $M_{4}$ level, ${ }_{4}$ the ionization crosssection may fary by up to a factor of 3 from $2: 4 \times 10^{-24} \mathrm{~m}^{2}$ with $\mathrm{E}_{\mathrm{f}}=15 \mathrm{keV}$ to $0.8 \times 10^{-24} \mathrm{~m}^{2}$. with $E_{1}=60 \mathrm{keV}$. Furthermore, energetic backscattered electrons coming from the entire range of the primary electron beam contribute for the most part to the yield of Auger electrons emitted by the specimen. By another way, the exit area of backscattered electrons becomes larger than the cluster size; so Auger peak height to background ratio is reduced.

The spatial resolution in Auger spectroscopy must be investigated in terms of lateral distribution of the Auger electrons which are emitted from the thin surface layer (8 A escape depth for $350 \mathrm{eV}$ silver Auger electrons) by both primary electrons and backscattered electrons. Before detection by the analyser, the true Auger profile results from the convolution of the incident beam with the angular backscattered electrons distribution. According to Gomati and Prutton (9), at low energies spatial resolution should scale to be about twice the beam size provided that the beam size is small compared with the backscattering area. At high energies, lateral distribution of backscattered electrons becomes important. The detection ability on small areas is illustrated in Figure 2 and 3 .
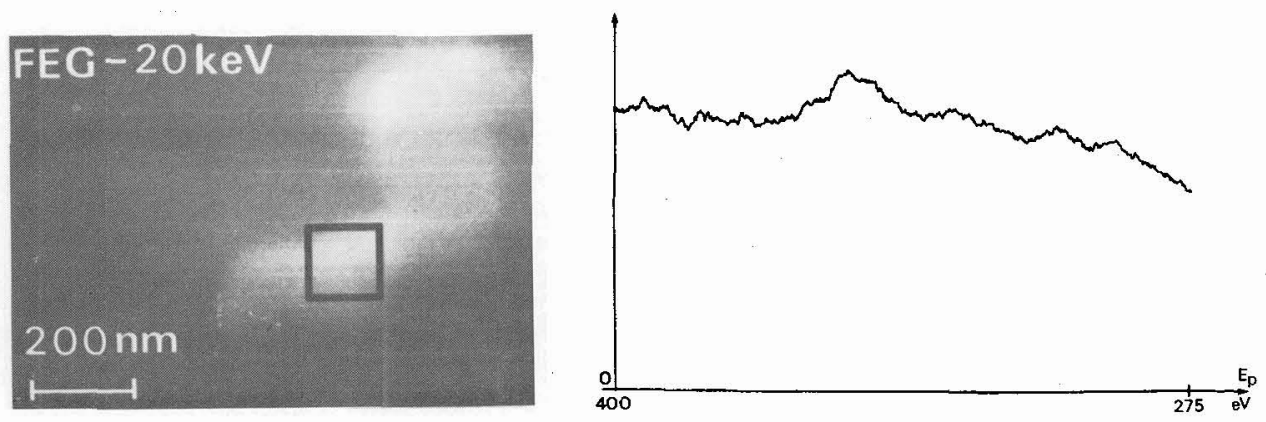

Fig. 2 - Silver particle on a silicon substrate : (a) micrograph at high magnification ; (b) Auger spectra obtained on this particle. [Primary energy : $20 \mathrm{keV}$; $\mathrm{CRR}=1$; current $: \sim 0.6 \mathrm{nA} ;$ sweep $: 0.4 \mathrm{~V} / \mathrm{sec}$. $\tau=3 \mathrm{~s}$; detection sensibility : $3 \mathrm{mV}]$.
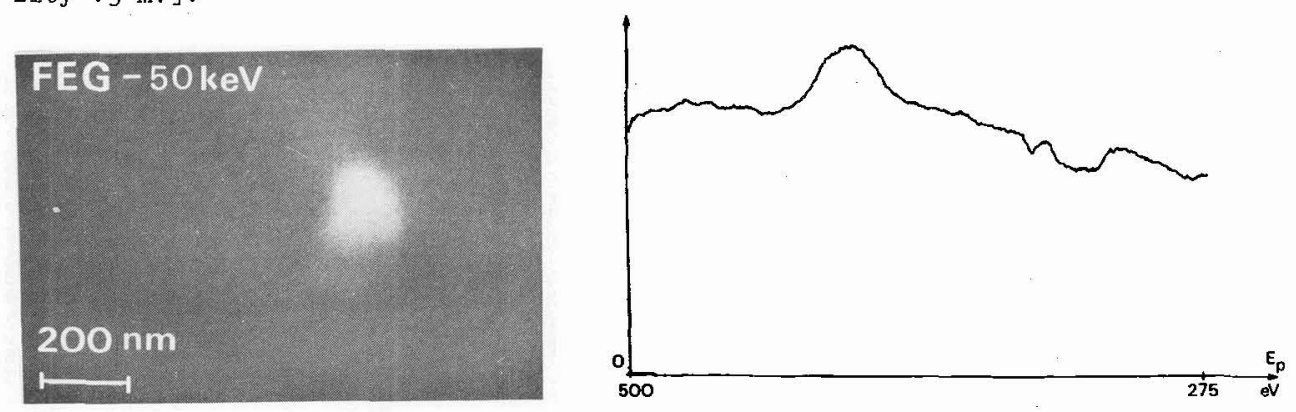

Fig. 3 - (a) and (b) : Silver particle on a silicon substrate. Auger analysis on a $75 \mathrm{~nm}$ size and spectra obtained for a $50 \mathrm{keV}$ primary energy in the same detection conditions (current $\sim 3.25 \mathrm{nA}$; detection sensibility : $10 \mathrm{mV}$ ). 
Figure 2 shows typical spectra obtained with a $200 \mathrm{~nm}$ silver cluster at $20 \mathrm{keV}$ primary energy. Figure 3 shows the spectra, obtained in the same detection conditions, with $50 \mathrm{keV}$ primary energy on a analysis size of $75 \mathrm{~mm}$. The smallest particles which have been detected at $50 \mathrm{keV}$ are $50 \mathrm{~nm}$ size.

Backscattered electrons influence is pointed out on the spectra of figure 4: in spot position on the

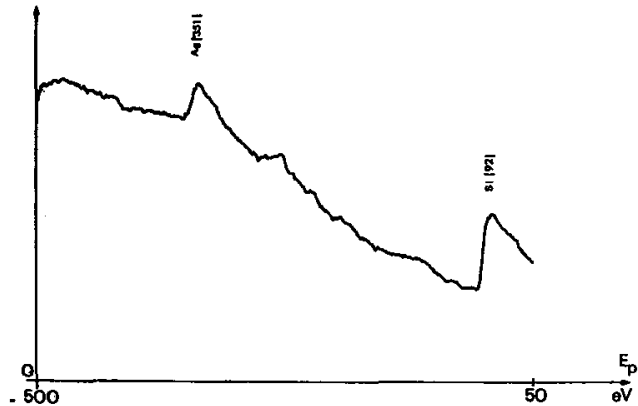

Fig. 4 - Primary energy $40 \mathrm{keV}$. Same detection conditions. silver cluster, Auger analysis reveals a large silicon peak (92 eV) initiated by the backscattered electrons in the substrate. Likewise, if an Auger analysis realized on $\mathrm{Si}$ substrate is made sufficiently near a cluster, a small silver peak can be observed. Lateral distribution of backscattered electrons on a specimen surface has been obtained using Monte-Carlo calculations (10) (11) (12). As an example, with a $30 \mathrm{keV}$ incident electron beam hitting the specimen at an incidence of $45^{\circ}$, the diameter at half maximum of the lateral distribution is approximately $1,4 \mu \mathrm{m}$ for silver and 4,6 $\mu \mathrm{m}$ for silicon.

In this case, backscattered electron effects represent the fundamental limitation of Auger analysis resolution.

\section{IV - Conclusion}

MicroAuger analysis of $50 \mathrm{~nm}$ silver island deposited on a silicon substrate has been demonstrated. Auger peak height to background ratio has been determined experimentally in the $5-60 \mathrm{keV}$ range. Optimizing this ratio needs excitation conditions using primary energies lower than $20 \mathrm{keV}$. For increase the beam current in this energy range and to avoid emission current drift, thermal-field built up tip is necessary. Tip heater circuit has been elaborated and checked in our microscope : beam current drift is eliminated and the residual fluctuations of the current are about $5 \%$.

Changes of the Auger peak height to background ratio and spatial resolution have been explained by means of backscattered electrons influence. To limit this effect, thin film Auger analysis studies with simultaneous STEM observations have been started.

\section{References}

1. Harris I.A., J. Appl. Phys. 39 (1968) 1419.

2. Christou A., J. Appl. Phys. 47 (1976) 5464.

3. Venables J.A., Jansen A.P., Akhter P., Derrien J. and Harland C.J., J. Microscopy 118 (1979) 351.

4. Venables J.A., Janssen A.P., Ultramicroscopy. $\underline{5}$ (1980) 297.

5. Browning R., Bassett P.J., El Gomati M.M., and Prutton M., Proc. R. Soc. Lond.

A. 357 (1977) 213 .

6. Kuyatt C.E. and Simpson J.A., Rev. Sei. Instr. 38 (1967) 103.

7. Shimizu R., Quantitative analysis by Auger electron spectroscopy, Toyota Foundation Research Report. Rep. NoI - 006 - No $76-0175$.

8. Powell C.J., Rev. of Modern Physics. 48 (1) (1976) 34.

9. El Gomati M.M. and Prutton M., Surface Science 72 (1978) 485.

10. Murata K., J. Appl. Phys. 45 (4) (1974) 110.

1.1. Vicario E. and Escudie B., Journal de microscopie et spectroscopie électroniques, 5 (1980) 357 .

12. Vicario E., Private communication. 